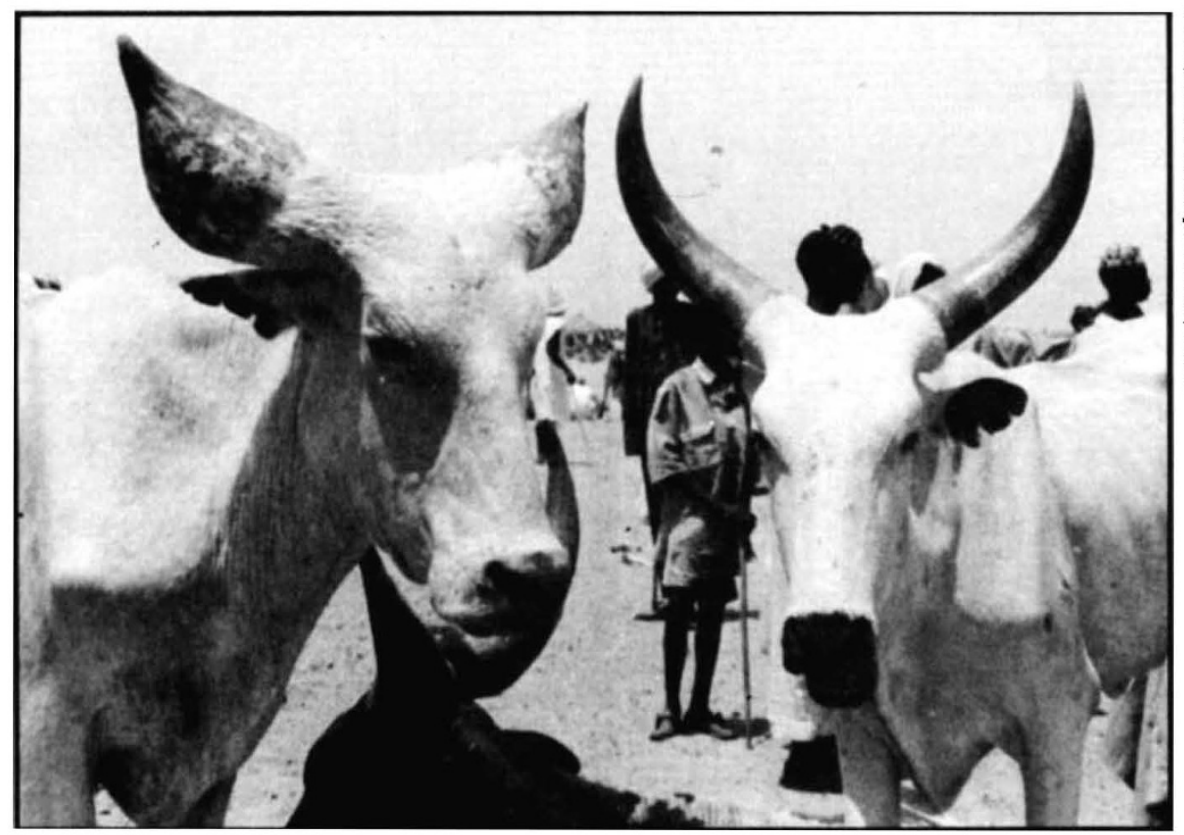

\title{
Conserving genetic resources
}

Many breeds of livestock and innumerable varieties of crops which have arisen in the course of man's agricultural history are now in grave danger of being supplanted by the comparatively fewer highly-bred animals and plants of modern agriculture. A priceless and irreplaceable reservoir of genetic raw material is threatened. Peter Collins looks at efforts now underway to preserve some of the rapidly vanishing breeds of livestock. Next week Eleanor Lawrence reviews international efforts to conserve crop genetic resources.

Concern for the fate of traditional breeds of livestock is an aspect of conservation that has as yet received little attention at the international level. It is true that cerain breeds, especially of cattle, that would otherwise have disappeared have been preserved by societies set up for this specific purpose. But most breed societies are at least as much concerned with the quality and performance characteristics of the breeds they represent as with conserving them as sources of genetic material. This is by contrast with the tremendous interest now apparent, and actively fostered over many years by the Food and Agriculture Organisation (FAO), in maintaining genetic stocks of crop plants.

Until fairly recently the specialised breed society was largely a British institution. Although this movement is now spreading, breed societies are still confined principally to the agriculturally more advanced countries, but even they have not prevented the disappearance of a number of ancient and potentially valuable breeds. Nowhere outside the UK is there anything approaching the Rare Breeds Survival Trust, a body specifically concerned with the conservation of British breeds of livestock that would otherwise become extinct.

Pure stocks of major commercial breeds have, of course, been maintained, especially where their performance is particularly in line with present thinking in the agro-economic field. But the number of such breeds has been declining for many years, and this process is accelerating rapidly. Thus, a recent FAO publication (Report of a Pilot Study by FAO and UNEP on Conservation of Animal Genetic Resources, Rome, March 1975) identifies 118 breeds of cattle in Europe and the Mediterranean Basin as being "in a relic state, in danger now, or in danger in the future." It records only 30 native breeds from the same group of countries as "not in danger”.

Among those already threatened with extinction are such familiar breeds as the Irish Kerry ("already in a relic state"), and the Red Poll and Beef and Dairy Shorthorns in the UK; even Scotland's Ayrshire is in danger of disappearing. The decline is particularly marked in the dairy breeds, as it is throughout Europe, on account of the tremendous rise in popularity of various types of Friesian. There has always been a certain amount of deliberate cross breeding in the livestock industry, relying on the maintenance of purebred stocks of the selected parent breeds. This aspect of conservation has scarcely been recognised, mainly because the objective has been increased performance and production of more and better meat and milk, and occasionally, disease resistance.

But it is this point of view that has, for very good reasons, principally influenced the FAO's approach to the problems of increasing livestock production in the developing countries. Thus, the FAO has frequently advocated the use of local breeds in these countries for crossing with introduced animals, but has not been greatly interested in the conservation of other, less immediately useful indigenous breeds. Now, there is increasing concern that the success of such introductions is beginning to erode the irreplaceable genetic resource that exists in traditional native African and Asian breeds. Many of these, it is feared, may disappear before there has been a chance to evaluate their performance under improved conditions, or for cross breeding with other local or introduced breeds.

With the sudden surge of interest in conservation, and more particularly, with the creation of the United Nations Environment Programme (UNEP), this situation has begun to change. UNEP has a specific objective in this field, based on a resolution of the Stockholm Environment Conference of 1972. This is "to initiate the preparation of a comprehensive catalogue of threatened species and varieties of crop plants, fish, domestic animals and micro-organisms, and to cooperate with the FAO in its programme for genetic resource conservation ..."

Earlier this year the FAO and UNEP published a report of their first joint project. The project-in effect, the first international step towards the conservation of genetic resources of domestic animals-has two objectives. First, "to prepare a preliminary list of breeds of farm animals which are in danger of extinction together with an account of any measures which have been recommended or taken to prevent this extinction"; and, second. an examination of the problems involved in the conservation of a single breed in a developing country.

A breed of humpless cattle known as the Kuri was chosen for the second part of the project. The Kuri, whose habitat is the islands and shores of Lake Chad, is unique in the possession of inflated, spongy horns, apparently (though exactly how is not known) an adaptation to its habits and habitat. A fine swimmer, the Kuri actually feeds 
in Lake Chad, eating the coarse forage of the shallow shores, and swims to and fro to reach new pastures. The concern about the survival of the Kuri, however, is based on a series of circumstances affecting, or liable to affect, many other breeds in developing countries.

Since 1960 , a rise in the water level of Lake Chad seems seriously to have reduced the available grazing area. Then, because of the demand for Kuri stock, which are described as moderate milkers and excellent beef animals, local farmers could obtain two zebu cattle for one Kuri. This cannot be avoided where numbers of cattle rather than quality is still important to local tribes, but the consequence is dilution of the Kuri herds with zebu blood. In addition, the Sahelian drought of recent years has led to pressure on the Kuri grazing areas by zebu herds from the Sahel.

The original project for the conservation of the Kuri was proposed in 1972 by the Lake Chad Basin Commission. The aim is to establish several herds of pure-bred Kuri, selected with an emphasis on the animals' economic qualities, but including one small herd specifically intended to preserve the unique, inflated, buoy-shaped horns which have attracted many travellers in the Lake Chad region-and which could make these Kuri a tourist attraction in themselves. In its latest form, with UNEP-FAO assistance, this project can be seen as a valuable exercise in the deliberate conservation of a threatened breed.

While most attention has so far been directed towards cattle, the situation is little different where other farm livestock are concerned. Many breeds of sheep, pigs, horses and even goats are in danger of becoming extinct, mainly for the same reasons: changes in the pattern of farming, improvement of land, and the constant demand for higher production based on the use of feeds not available in the 'natural' environment. Other domesticated animals, such as the camel and its South American relatives, have scarcely been considered from the conservation point of view; a minor species such as the donkey could well disappear simply because no one has thought of doing anything to prevent this happening.

In general, there are three aspects of this conservation problem: cultural, scientific and economic. The traditional breeds of livestock are, first of all, as much a part of our cultural heritage as are ancient buildings and works of art. From the scientific point of view, certain breeds have colour genes. The larger species, too, are useful as controllable sources of milk, blood and various tissues of particular genetic interest.
But it is the practical economic argument that is the most important. The classic example of this is probably the "discovery" by American poultry breeders of the traditional Cornish breed, reduced in its home country to a purely fancy bird. Crossed with other breeds, it made possible the rapid growth on which the modern broiler industry depends.

Similarly, remote breeds of sheep, for example from Greece and Finland, were unknown beyond their own homelands until, because they were highly prolific, they were seen to be suited to modern husbandry techniques. There are several very prolific tropical breeds of sheep, too, in the Caribbean, in Latin America, West Africa and South-east Asia, that could also be useful.

An even more important example is probably that of the 'trypanotolerant' indigenous cattle of various West African countries. If these could be successfully crossed, or developed under improved conditions to provide a more economic yield of meat and milk, it might be possible to avoid the enormous cost of controlling tsetse fly, the vector of trypanosomiasis, which denies thousands of square miles of Africa to the livestock industry.

One apparent problem, however, is the lack of knowledge of the characteristics of most of the indigenous breeds of the developing countries. A first step, which must come before a conservation programme can be set up for any breed, is obviously its evaluation in terms of production, disease resistance, and potential when crossed with other, better known breeds. This means a long and enormously costly series of projects.

Moreover, even where there have been apparently successful cross-breed-

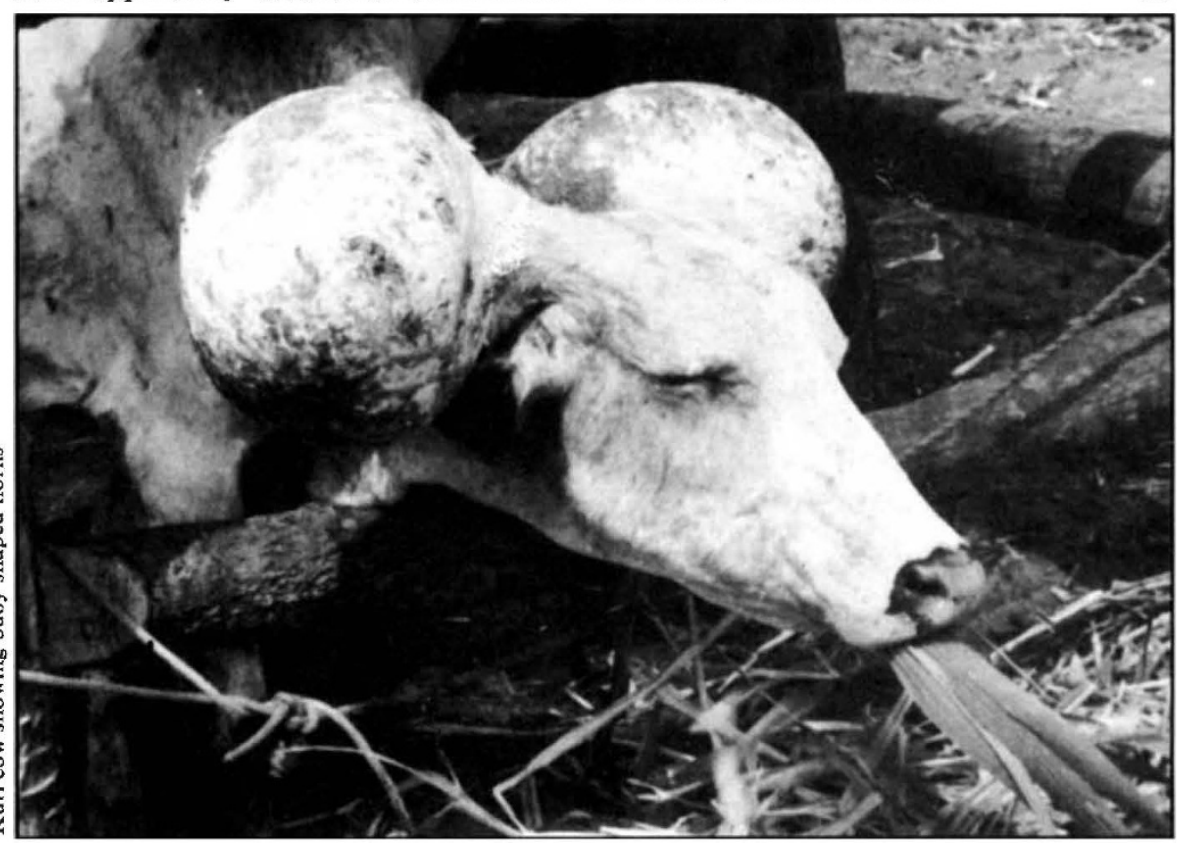

ing programmes, little is sometimes known about what is happening from the genetic point of view. Thus, it was long considered that the "hybrid vigour" (heterosis) apparent when certain exotic, highly developed breeds have been crossed with local stock, was due to the introduced, often larger animal. Now it seems that this is not necessarily the case, and it is essential that sufficient pure-bred herds of the local breed be maintained if such cross breeding is to be continually successful. An example is quoted of the local Criollo cattle in South America, which have been successfully crossed with Brahman (zebu) bulls from the United States. Now the Criollo themselves are in danger of dying out, and the genetic resource they represent could be lost.

Conservation of livestock breeds for economic or cross-breeding purposes demands the maintenance of considerable herds of pure-bred stock, which many of the poorer developing countries may not be able to afford. This therefore is a case for international action. Where a breed is being maintained for scientific purposes, smaller herds, such as might be kept in rare animal parks or large zoos such as Whipsnade, will suffice. Where the interest is solely cultural or historic, such as in the case of the UK's White Park cattle at Cadzow and Chillingham, even fewer beasts need be kept and the problem of cost may be less important than that of management. Certainly, some of the hundreds of breeds of livestock now kept on the world's farmlands will disappear. But with the new approaches to agriculture, and the call to combine higher production with better use of animal and plant resources, everything must be done to ensure that as little as possible of the genetic heritage available in these breeds is lost. 